\title{
Erratum: Neurological Manifestations in Familial Mediterranean Fever: Results of 22 Children from a Reference Center in Kayseri, an Urban Area in Central Anatolia, Turkey
} \author{
Ali Yikilmaz ${ }^{4}$ Munis Dundar ${ }^{5}$ Huseyin Per ${ }^{1}$ \\ ${ }^{1}$ Division of Pediatric Neurology, Department of Pediatrics, Erciyes \\ University, Faculty of Medicine, Kayseri, Turkey \\ ${ }^{2}$ Division of Pediatric Nephrology and Rheumatology, Department of \\ Pediatrics, Erciyes University, Faculty of Medicine, Kayseri, Turkey \\ ${ }^{3}$ Division of Pediatric Nephrology, Department of Pediatrics, \\ Erciyes University, Faculty of Medicine, Kayseri, Turkey \\ ${ }^{4}$ Department of Radiology and Pediatric Radiology, Erciyes \\ University, Faculty of Medicine, Kayseri, Turkey \\ ${ }^{5}$ Department of Medical Genetics, Erciyes University, Faculty of \\ Medicine, Kayseri, Turkey
}

Mehmet Canpolat ${ }^{1}$ Hakan Gumus $^{1}$ Zubeyde Gunduz ${ }^{2}$ Ruhan Dusunsel ${ }^{2}$ Sefer Kumandas ${ }^{1}$ Ayşe Kaçar Bayram ${ }^{1}$ Sibel Yel ${ }^{3}$ Hatice Gamze Poyrazoglu ${ }^{1} \quad$ Kenan Yilmaz $^{3}$ Selim Doganay ${ }^{4}$

Neuropediatrics 2017;48:402.
Address for correspondence Ayşe Kaçar Bayram, MD, Division of Pediatric Neurology, Department of Pediatrics, Erciyes University, Faculty of Medicine, 38039, Melikgazi, Kayseri, Turkey (e-mail: draysebayram@gmail.com).

\section{ERRATUM}

It has been brought to the Publisher's attention that there is an error in the following sentence in the abstract of the above article published in Neuropediatrics, Volume 48, Number 2, 2017, page 79 (DOI: 10.1055/s-0036-1593374): Neurological findings included headache in 16 patients (72.7\%), epilepsy in 6 patients (27.3\%), pseudotumor cerebri in 2 patients (9.1\%), multiple sclerosis in 1 patient (4.5\%), and tremor in 1 patient (4.5\%). The correct sentence should actually be "Neurological findings included headache in 16 patients (72.7\%), epilepsy in 6 patients (27.3\%), pseudotumor cerebri in 2 patients (9.1\%), tremor in 2 patients (9.1\%), and multiple sclerosis in 1 patient (4.5\%)." 